\title{
L'USAGE POLITIQUE DU MYTHE AU NÉPAL. UNE LECTURE ETHNO-HISTORIQUE DU DIEU MATSYENDRANÂTH
}

GÉRARD TOFFIN

La théorie des trois fonctions indo-européennes s'applique-t-elle au monde hindou post-védique ? Georges Dumézil le pensait qui s'est employé à identifier des traces de cet ancien héritage commun aux peuples indo-européens dans certains textes et institutions du brâhmanisme classique : le système quadripartite des " ordres » varna, la classification des différents types de mariage dans les traités de droit, la série des cinq héros Pânụava de l'épopée du Mahâbhârata, etc. Daniel Dubuisson, un disciple de Dumézil, a tenté il y a peu d'étendre cette approche au Râmayâna, l'autre grande épopée de la littérature indienne, composée probablement à l'aube de notre ère ${ }^{1}$. Tout se serait donc passé comme si le vieux fonds idéologique des Indo-Européens attaché à la souveraineté magico-religieuse, à la force militaire et à la prospérité avait survécu dans le temps et avait continué, malgré le contact avec des populations autochtones non aryennes, à inspirer des types de classification ou des modèles sociaux.

S'il a fait ses preuves pour la tradition védique ${ }^{2}$, ce schéma tripartite cadre cependant assez mal avec le monde hindou classique. On est d'abord constamment gêné par le fait que les ordres sociaux varna sont au nombre de quatre et non de trois. Certes, il est toujours possible de postuler, comme le fait Dumézil ${ }^{3}$, que les Çudra ont été rajoutés postérieurement aux trois premiers (Brâhmane, Kșatriya, Vaiçya ou Viç) de manière à intégrer la masse des peuples autochtones soumis par les Indo-Européens. On peut aussi, c'est vrai, remarquer que le quatrième varna continue, même à l'époque classique, à s'opposer en bloc aux trois premiers, lesquels sont liés par un triple devoir commun : l'étude, le sacrifice, le don. Il n'empêche que les textes hindous raisonnent en termes de quadripartition plus que de tripartition et que la casuistique théologique indienne qui cherche à concilier les deux apparaît peu convaincante.

Plus fondamentalement encore, les deux premières fonctions correspondent assez mal à la division en Brâhmanes et Kșatriya qui constitue pourtant une 


\section{AUTOUR DU RELIGIEUX}

dualité centrale dans la pensée hindoue. Les Brâhmanes, membres du premier varna indien, ne possèdent en effet aucune parcelle de souveraineté temporelle ; ce sont (en principe) des prêtres voués entièrement à la vie religieuse. Les Kșatriya en revanche, deuxième varna de la tétrade hindoue, ne sont pas seulement des guerriers ; ils symbolisent aussi, surtout devrait-on dire, la royauté, avec sa dimension religieuse propre. "Le Kșatriya par excellence est le roi : c'est l'attraction du pouvoir royal qui a commandé l'orientation de la classe tout entière ${ }^{4}$. La théorie des trois fonctions appliquée à l'Inde classique gomme donc le clivage essentiel entre ces deux premiers varna $a^{5}$. Quant à l'aspect double de la souveraineté mis en évidence par Dumézil dans maintes représentations indo-européennes, en particulier dans le couple védique Mitra-Varuna, il déborde largement de la catégorie des Brâhmanes et doit être pensé, en Inde, à travers la paire formée par le roi et son prêtre-chapelain.

Il y a donc eu altérations au fil des années, déplacements, sans doute imposés par le contexte culturel nouveau. Il ne nous est pas possible de discuter ici de cette évolution qui a conduit le vieux système triparti à associer davantage la royauté à la deuxième fonction et à mêler souveraineté et aspects religieux. Cette histoire, qui risque fort de rester à jamais conjecturale, mériterait une étude spécifique. Quoi qu'il en soit, il faut considérer que la seule triade véritablement pertinente pour l'époque post-védique est celle qui divise le corps social en prêtre Brâhmane, roi-guerrier Kșatriya et agriculteur-commerçant Vaiçya, trinité à laquelle s'ajoutent les serviteurs Çudra qui se distinguent relativement des trois premiers. Cette triade, ou plus exactement cette tétrade d'un strict point de vue hindou, pénètre tous les éléments de la pensée religieuse et commande de multiples représentations intégrées aux structures globales de l'univers. C'est d'elle que naît l'équilibre, tout théorique, de cette société strictement hiérarchisée. Il est bien évident qu'elle est en rapport avec la structure védique ancienne (et plus généralement indo-européenne) que Dumézil a brillamment dévoilée. Elle n'en possède pas moins ses particularités.

Il est un point de l'œuvre de Dumézil sur lequel les commentateurs ont peu insisté, c'est la présence aux côtés des éléments trifonctionnels d'une figure divine ou héroïque complémentaire qui en fait la synthèse. Cette figure ne se cantonne pas dans une seule des trois fonctions, mais se situe et opère dans toutes. Le plus souvent elle est féminine. Dans l'Inde védique, c'est Çri ou Saravastî ${ }^{6}$; dans l'Inde de l'épopée, ce serait Draupadî, la commune épouse des cinq frères Pândava? . Parfois elle est masculine. C'est le cas en particulier d'Agni : " En tout lieu et en toutes choses, Agni se trouve chez lui et un hymne entier (Rv. 2, 1) est consacré à l'identifier à la plupart des dieux. Mais il est plus spécialement triple, en rapport par exemple avec les trois niveaux de l'univers, et avec les dieux de ces niveaux ${ }^{8}{ }^{8}$. La même chose vaut pour les Açvin Récemment, Dubuisson a reconnu dans cette configuration trivalente un type possible de structure trifonctionnelle parmi d'autres et a fait considérablement avancer la discussion en rappelant que le roi indien faisait lui aussi la synthèse des trois fonctions dans sa personne ${ }^{10}$. Même dans l'épopée, un roi parfait doit posséder les qualités associées à chacune des trois fonctions et coordonner les trois classes hiérarchisées (prêtres, rois-guerriers et éleveurs-agriculteurs) dont est constituée la société.

On entend verser au dossier de ces figures trivalentes une étude sur le 
Matsyendranâth népalais. Il s'agira plus particulièrement de Râto Matsyendranâth, le Matsyendranâth rouge, qui est vénéré sous divers noms dans ce royaume himalayen depuis le $\mathrm{VII}^{\mathrm{e}}$ siècle. Le culte de cette divinité est circonscrit à la vallée de Kathmandou, qu'on appelait jusqu'au XviII ${ }^{e}$ siècle la vallée du Népal, nepâl mandala, et dans laquelle s'est développée une civilisation de très haut niveau fortement influencée par l'Inde. Bien qu'elle soit située à la périphérie des grands centres de brahmanité de la plaine indo-gangétique et qu'elle soit peuplée majoritairement par une population hétérogène aux traits mongoloïdes et de langue tibéto-birmane, les Néwar ", cette vallée a constitué dès le $\mathrm{v}^{\mathrm{e}}$ siècle après $\mathrm{J}$.-C. un avant-poste de la civilisation indienne. Elle a reçu les éléments majeurs de sa culture du sous-continent et est puissamment irriguée par la pensée indienne, bouddhiste et hindoue. L'un des objectifs de cet article est de montrer que Râto Matsyendranâth (désormais Matsyendranâth sauf avis contraire) possède un aspect trivalent indiscutable. Il a paru intéressant de reconstituer le contexte dans lequel cette trifonctionnalité émergea et de la situer dans les termes de l'époque. Car ce sont des facteurs historiques circonstanciels plus qu'un vieil héritage védique qui expliquent cette figure polyfonctionnelle. Les aspects synthétiques de Matsyendranâth doivent en particulier être mis en rapport avec les fonctions régulatrices des rois Malla, maîtres de la Vallée du XIII ${ }^{e}$ siècle au XvIII ${ }^{e}$ siècle, et avec la faculté que ces souverains avaient d'utiliser les symboles religieux pour asseoir leur pouvoir.

Précisons au préalable que la vallée de Kathmandou dont il sera question ici est une région fortement chargée d'histoire. Elle nous a légué un grand nombre de témoignages écrits, soit sous forme d'inscriptions, dont les plus anciennes remontent au $\mathrm{v}^{\mathrm{e}}$ siècle après J.-C., soit sous forme de manuscrits sur feuilles de palme ou de papier, les premiers datant des $\mathrm{IX}^{\mathrm{e}}-\mathrm{X}^{\mathrm{e}}$ siècles. Cette vallée a même été souvent décrite comme un véritable musée vivant de l'Inde ancienne, tant elle a conservé d'éléments aujourd'hui disparus de l'Inde proprement dite. Elle a su accueillir à divers moments de son histoire des groupes de population d'origine indienne qui, fuyant telle ou telle invasion, telle ou telle guerre, lui ont permis de maintenir un contact avec les sources vives de l'indianité. Ce passé se fait sentir partout de nos jours, aussi bien dans les villes que dans les campagnes. Il continue de régir pour une grande part les conduites et les valeurs des Néwar, la population la plus anciennement installée dans ce bassin. Malgré l'effondrement des royaumes Malla à la fin du XVIII ${ }^{e}$ siècle et leur insertion dans un ensemble national népalais, malgré l'occidentalisation rapide depuis 1951 qui pousse à un désengagement des sphères du sacré et du profane, la vie sociale et religieuse du nepâl mandala contemporain tire toujours ses fondements de la période Malla (XIII ${ }^{\mathrm{e}}$ siècle-XVIII ${ }^{\mathrm{e}}$ siècle), véritable âge d'or de la civilisation qu'il est convenu d'appeler néwar ${ }^{12}$. En dépit des transformations économiques et politiques, le rapport au surnaturel et au sacré, notamment, a peu changé. Les temples, qui datent à peu près tous de cette période, ainsi que le système des castes, qui, lui, est implanté depuis plus longtemps, continuent de jouer un rôle décisif dans la société et de donner à ses membres le sentiment d'appartenir à une totalité organique. Entre le présent et le passé, une même structure mentale se fait sentir que seuls des changements récents menacent. Pour saisir une telle civilisation, l'ethnographie, qu'elle soit villageoise ou urbaine, ne peut constituer, on le comprend bien, qu'une première étape. La recherche doit être 
complétée par une approche historique qui, quoique fortement "anthropologisée ", reste attachée à situer les principaux éléments culturels et sociaux observés dans une perspective diachronique. C'est ce que je me propose d'entreprendre à partir d'un cas précis.

\section{Matsyendranâth, une divinité composite}

Le nom Matsyendranâth appliqué à ce dieu népalais ne remonte pas au-delà du XVIII ${ }^{\mathrm{e}}$ siècle. Dans les sources antérieures, le dieu est appelé soit par une série de mots sanscrits : Karunâmaya, "fait de compassion », Avalokiteçvara, Lokeçvara, " le Seigneur du monde », Lokanâth, « le Maître du monde ", Padmapâni, " qui tient un lotus à la main », soit par un nom tibéto-birman : Bunga dya, lié au nom du village dans lequel se trouve le licu de culte principal du dieu (Bunga, Bungamati), et qui signifie en néwari : plan d'eau, source dans un champ. Pour la grande majorité des Néwar, le dieu de Bungamati est aujourd'hui encore appelé Bunga dya (ou Karunâmaya pour les hautes castes bouddhistes), jamais Matsyendranâth. En revanche, c'est sous ce dernier nom que les non-Néwar, c'est-à-dire les Indo-Népalais qui conquirent la vallée du Népal au XVIII ${ }^{\mathrm{e}}$ siècle et détrônèrent les rois Malla, connaissent cette puissance divine ${ }^{13}$.

D'après la vieille chronique Gopâlarâjavamçâvalî du XIve siècle, dont la fiabilité est largement reconnue, le dieu (Bugma Lokeçvara) aurait été introduit au Népal au $\mathrm{VII}^{\mathrm{e}}$ siècle par le roi Narendradeva pour mettre fin à une longue sécheresse ${ }^{1+}$. Ce souverain aurait été chercher Matsyendranâth au Kamarupa (= Assam), dans l'Himalaya oriental. Le dieu fut installé dans un temple, probablement à Bungamati, au sud de Patan, et une fête annuelle instaurée en son honneur. Cette tradition, très ancienne, semble historiquement avérée. La première évidence sur le Matsyendranâth népalais, un document iconographique représentant Râto Lokeçvara, ne date pourtant que du XI ${ }^{\mathrm{e}}$ siècle ${ }^{15}$. Deux cents ans plus tard, le moine tibétain Dharmasvamin, qui séjourna au Népal de 1228 à 1234, parle d'une fameuse statue en bois de santal et de couleur rouge d'Avalokiteçvara dans le monastère de Bu-kham (= Bungamati) et fait allusion à la fête de la divinité ${ }^{16}$. A partir des XIV ${ }^{e}-X^{e}$ siècles, les sources deviennent de plus en plus abondantes et précises, surtout sur le cycle festif.

Bunga dya-Avalokiteçvara est une divinité extrêmement complexe, l'une des plus composites du panthéon de la vallée du Népal. Elle résulte de la fusion de plusieurs figures divines indépendantes au cours d'une histoire qui s'étend sur plus de dix siècles. Au départ, on a probablement une divinité bouddhiste, Karunâmaya ou Avalokiteçvara, dieu dont le culte était très répandu dans la vallée du Népal au vi ${ }^{\mathrm{e}}$ siècle si l'on en juge d'après les vestiges archéologiques. Dès cette époque, les prêtres desservants du dieu devaient être bouddhistes, comme c'est toujours le cas aujourd'hui. Reste que ce dieu a pris rapidement une coloration particulière au contact du milieu hindou et qu'il a acquis une importance rarement égalée dans les pays asiatiques voisins. De sorte que la question se pose : s'agit-il d'une vieille divinité locale, tibéto-birmane, adoptée et rebaptisée au $\mathrm{v}^{\mathrm{e}}$ siècle par les bouddhistes ? Ou bien la figure, première, d'Avalokiteçvara s'est-elle popularisée, folklorisée, néwarisée en quelque sorte 
en se chargeant ultérieurement d'éléments tibéto-birmans ? Les travaux les plus récents font pencher pour la seconde hypothèse ${ }^{17}$. Comme on l'a fait remarquer, les aspects féminins ${ }^{18}$ attachés à Bunga dya ne militent pas forcément en faveur d'une divinité proto-aryenne, car Avalokiteçvara a aussi de tels aspects androgynes dans divers pays d'Extrême-Orient ${ }^{19}$. Il est également difficile d'arguer du nom néwari du dieu pour faire de ce dernier une figure tribale, car toutes les divinités du panthéon néwar possèdent encore aujourd'hui un surnom populaire à côté du nom sanskrit. La seconde hypothèse correspond par ailleurs mieux à la maigre chronologie que l'on peut réunir sur les tout premiers débuts du culte.

Par la suite, Bunga dya-Avalokiteçvara fut rebaptisé Matsyendranâth (ou Machendranâth) - un mot indien lui aussi - sans doute au XvirI siècle, sous l'influence du çivaisme et plus particulièrement des Kânphatâ Yogî. Cette secte tantrique, née en Inde vers la fin $d u \mathrm{x}^{\mathrm{e}}$ siècle après J.-C., joua un rôle capital dans l'histoire religieuse de la vallée du Népal ${ }^{20}$. Les Kânphatâ sont liés au culte des Nâth, à la fois maîtres spirituels et divinités tutélaires, au nombre canonique de neuf. Parmi eux Gorakhnâth, le fondateur présumé de la communauté sectaire, et Matsyendranâth - sans doute deux personnages historiques évhémérisés. Très vite, le culte de ces dieux s'imprégna de pratiques tantriques et yogiques. La première référence au nom de Matsyendranâth à propos de Bunga dya date de $1748^{21}$. Cette appellation se répandit ensuite progressivement, surtout après la conquête Gorkhâli de la Vallée en 1768 . Aux XIX ${ }^{\mathrm{e}}$ et $\mathrm{XX}^{\mathrm{e}}$ siècles, les chroniques écrites en népali emploient exclusivement le nom de Matsyendranâth pour désigner la divinité de Bungamati.

Râto Matsyendranâth possède aujourd'hui deux temples dans la vallée de Kathmandou : la résidence principale à Bungamati (néw. : Bunga) où il est gardé six mois par an, de juin jusqu'à novembre ou décembre, et l'autre à Patan, l'une des plus anciennes villes du Népal, où il réside le reste de l'année. Les prêtres sont choisis au sein de la communauté bouddhiste Vajrâcârya et Çâkya de Bungamati. Au nombre de trente, ils se relaient pour assurer le culte du dieu. La fête annuelle a lieu au printemps, d'avril à juin, période de l'année qui coïncide avec la fin de la saison sèche et l'approche de la mousson. Le premier jour de Baiçâkh (avril-mai), quinzaine sombre, la statue de la divinité est tout d'abord lavée de manière cérémonielle. Elle est repeinte et décorée. Puis vient la fête du char. Pendant un mois et demi environ, Matsyendranâth fait le tour de la ville de Patan sur un char à quatre roues surmonté d'une flèche haute d'une vingtaine de mètres, recouverte de branchages. Il est suivi par un autre char, de dimensions plus réduites, sur lequel est placé le dieu Mînanâtha (ou Câkuwâ dya en néwari proprement dit), que les habitants désignent comme le frère cadet d'Avalokiteçvara - Matsyendranâth. Le dernier jour de la procession, la fête prend une dimension nationale. Devant une foule immense, les prêtres bouddhistes juchés sur le char du dieu exposent aux participants la chemise dorée (nép. : bhoto) de la divinité. Cette cérémonie, qui se tient à Jaulakhel, au sud-ouest de Patan, constitue le point d'orgue de la fête : aujourd'hui encore, le roi du Népal y assiste pour rendre hommage à la divinité. Aussitôt après, les chars sont démontés et les prêtres retournent à Bungamati avec la statue du dieu. A part quelques modifications mineures, l'essentiel du rituel festif actuel n'a pas changé depuis le XVII ${ }^{\mathrm{e}}$ siècle. 


\section{AUTOUR DU RELIGIEUX}

\section{Une synthèse des trois fonctions}

Matsyendranâth n'est pas attaché à une seule fonction. Il couvre toutes les provinces de la vie sociale et religieuse, notamment celles qui sont associées aux valeurs spirituelles ultimes, à la souveraineté royale et à la prospérité matérielle. On retrouve dans cette tripartition la triade : homme sacré, homme royal et guerrier, et homme producteur.

\section{Les valeurs spirituelles ultimes}

On peut distinguer deux versants. Côté bouddhiste, la figure importante est Karunâmaya. Cette puissance divine, supérieure, bienfaisante, exprime le surnaturel, le détachement des biens de ce monde. Les traits paisibles sous lesquels elle est représentée en statue renvoient aux aspects lumineux, somme toute très " mitriens ", associés à ce dieu.

Côté hindou, on a Matsyendranâth et ses relations obligées avec les Kânphatâ Yogî. Ici aussi ce sont les valeurs religieuses les plus élevées qui sont mises en valeur, celles qui poussent l'homme à se libérer de son vivant de ses chaînes karmiques au moyen d'exercices yogiques particuliers et à éprouver l'unité avec le cosmos en fusionnant les principes opposés du masculin et du féminin. Transcendance et au-delà libérateur, voilà les deux termes clefs. Pour les Kânphatâ, la quête de l'absolu n'est pas distincte de celle de l'immortalité et de la non-dualité dans la perfection du corps. Cette voie se conjugue à un mouvement sectaire qui a ses affiliés initiés et qui est basé sur l'élection de quelques adeptes à ce qui est considéré comme la pleine vie sacrée, seul but valable de l'existence.

\section{Le roi et Matsyendranâth}

Observons d'abord qu'Avalokiteçvara - Matsyendranâth est lui-même de descendance royale. Il est le fils du roi des Yakșa (démons) et son guru est Yama, le dieu de la mort, autre figure royale (Yama Râj) dans le panthéon hindou. Fait exceptionnel ? Non. Avalokiteçvara se voit souvent dépeint en Asic sous des traits royaux, et le roi est parfois vu, chez les Khasa de l'Ouest népalais du $\mathrm{xII}^{\mathrm{e}}$ siècle au $\mathrm{XIV}^{\mathrm{e}}$ siècle ou dans le Cambodge d'Angkor par exemple, comme une incarnation d'Avalokiteçvara ${ }^{22}$.

Il existe en vérité une relation intime entre Avalokiteçvara-Matsyendranâth et le roi. Les incidents qui surviennent lors de la procession du char divin dans les rues de Patan et les rêves que l'on peut faire au sujet de ce dieu ont une valeur prémonitoire pour la royauté et engagent directement l'avenir du royaume. Un agriculteur Jyâpu fit ainsi un rêve prophétique sous le règne de Ranajit Malla (1722-1769). Dans le songe, Matsyendranâth offrait au dieu Bhairavnâth de se rendre à Gorkha et d'y exercer le pouvoir. Bhairavnâth donna son accord, mais exigea au préalable que la vallée du Népal fût gouvernée par la maison royale de Gorkha. Matsyendranâth accepta et le Jyâpu en tira l'augure, bientôt vérifié, que les rois de cette principauté conquerraient un jour les trois royaumes de la vallée du Népal ${ }^{23}$. Citons également ces deux petits 
épisodes tirés des chroniques. En 1762, des larmes coulèrent de la statue du dieu. Signe funeste. Le roi de Bhaktapur mourut quelques jours plus tard ${ }^{24}$. En 1705 , le timon du char se brisa, on fut obligé d'interrompre la fête : un mois passa et le roi Yoganendra Malla décéda ${ }^{25}$.

Au xviI ${ }^{e}$ siècle, Bunga dya devint la divinité d'élection, istadevatâ, du roi de Patan et des monnaies furent frappées à l'effigie du dieu (Çrî Loknâth). Une inscription de 1675 va jusqu'à comparer le souverain au plant de lotus qui pousse aux pieds de la figure divine ${ }^{26}$. Matsyendranâth fait figure à cette époque de divinité royale, associée directement à la souveraineté, au même titre que Paçupatinâth, le dieu tutélaire de la vallée de Kathmandou, élément essentiel aujourd'hui de l'identité nationale. Srinivas Malla (règne : 1661-1684), l'un des rois qui fit le plus pour Matsyendranâth, est souvent décrit comme le " fils » de Karunâmaya. Quant à son père (géniteur...), le roi Siddhinarasimha Malla, qui régna de 1620 à 1661, il aménagea selon les chroniques récentes un jardin dans son palais et le divisa en trois parties dédiées chacune à un dieu particulier : Taleju, Degutale et Matsyendranâth ${ }^{27}$. Ce dernier se voit ainsi classé aux côtés de deux autres divinités palatiales qui entretenaient des liens privilégiés avec le souverain : Taleju, dont le roi tirait sa force, et Degutale, qui assurait la continuité de la dynastie Malla ${ }^{28}$.

On comprend dès lors mieux pourquoi les inscriptions et les chroniques énumèrent avec un tel luxe de détails les donations que les souverains faisaient au dieu et les embellissements qu'ils apportaient à son temple. Srinivas Malla, encore lui, peut s'enorgueillir d'avoir complètement réorganisé le culte du dieu et d'avoir fixé avec une grande précision les tâches auxquelles les castes de service étaient liées vis-à-vis de Matsyendranâth ${ }^{29}$. D'ailleurs, à cette époque, les rois (de Patan) étaient présents physiquement à de multiples moments de la fête, ils suivaient la procession à pied et aidaient parfois à tirer les cordes du char ${ }^{30}$. Aux XVII ${ }^{e}$-XVIII ${ }^{e}$ siècles, Matsyendranâth et son culte faisaient partie des symboles religieux, des regalia dont le pouvoir royal s'entourait et qui lui servaient à légitimer son autorité aux yeux de la population. Le lien entre le roi et le dieu était si fort qu'en 1709, lorsque le roi de Patan Indra Malla mourut peu avant le rite annuel du bain du dieu, on dut aller chercher un fils de Yoganarendra à Gorkha, Mahindra Malla. Aucun rite ne pouvait être célébré en l'absence du souverain ou de quelqu'un de sa famille ${ }^{31}$.

\section{La pluie et le riz}

Comme on l'a vu plus haut, Matsyendranâth est un dieu distributeur de pluie. C'est à la suite d'une longue sécheresse que la divinité fut introduite au Népal. Dès qu'il pénétra dans la Vallée, raconte la légende, Gorakhnâth, qui bloquait les serpents Nâga sous son corps, se leva pour accueillir Avalokiteçvara : " Les neuf Nâga ainsi libérés se dressèrent, entrèrent dans un nuage noir d'où ils saluèrent Lokanâth et firent tomber la pluie ${ }^{32}$. La fin de la fête correspond d'ailleurs approximativement au début de la saison humide et l'on pense aujourd'hui encore qu'il se met à pleuvoir le jour de l'exposition de la chemise du dieu à Jaulakhel (bhoto jâtrâ) ${ }^{33}$. Tout le cycle festif peut être vu comme un rituel d'appel de pluie, magnifié et patronné par le pouvoir royal. Le timon du char représente, dit-on, Kârkotaka Nâga, le roi des dieux-serpents 
- divinités elles aussi intimement associées à la pluie - et les cordes dont on se sert pour tirer le char symbolisent d'autres Nâga, maîtres du sol de la vallée du Népal. Le nom néwari du dieu lui-même évoque les affinités aquatiques de Matsyendranâth.

Matsyendranâth est aussi le dieu du riz, plus exactement celui qui introduisit cette plante dans la vallée de Kathmandou. La version néwari du mythe d'origine du dieu et la tradition vivante des villages d'agriculteurs du district de Patan concordent sur ce point ${ }^{3+}$. Plusieurs éléments du rituel festif mettent l'accent sur cette fonction agricole. Les fidèles par exemple offrent surtout des grains de riz (non cuit) au dieu. C'est ce qui fait dire à J.K. Locke: "Matsyendranâth fait tomber la pluie qui permet au riz de pousser et les habitants manifestent en retour leur dévotion à son égard en lui of frant des grains de riz $"{ }^{35}$. Il semble que ce dieu soit tenu directement pour responsable de la nourriture des habitants de la Vallée. Une légende raconte : " Matsyendranâth ne laisse jamais personne sans manger. Un jour, sa mère voulut le mettre à l'épreuve. Elle cacha à l'insu de son fils un insecte dans une petite boîte et l'enveloppa de plusieurs couches de tissu. Le lendemain matin, elle ouvrit la boîte. A sa grande surprise, l'insecte était en train de manger un grain de riz. La mère comprit que c'était là l'œuvre de Matsyendranâth et que son fils était le principal agent de la vie sur terre $\gg{ }^{36}$. Le riz est également présent dans le nom néwari de la divinité annexe Minanâtha : Cakuwâ dya, où l'on reconnaît le mot wâ qui - est-ce un simple hasard ? - signifie à la fois riz (non décortiqué) et pluie dans cette langue ${ }^{37}$. Les deux aspects sont indissolublement liés à Matsyendranâth dans les représentations populaires. Ainsi, le dernier jour de la fête, lorsqu'on démonte le char du dieu, plusieurs personnes se rassemblent autour du lotus en cuivre et d'un panier de bambou qui ont été placés à côté de la statue de Matsyendranâth au début des festivités. Si ces deux objets tombent par terre d'une certaine façon, c'est le signe qu'il pleuvra abondamment cette année-là et qu'on peut être assuré d'avoir une bonne récolte ${ }^{3 x}$.

\section{Les trois héros du mythe : un thème triparti}

On le voit, Matsyendranâth réunit en sa personne les trois fonctions, il en fait la synthèse, comme le roi hindou concentre en lui les aspects liés au sacré (au moins certains d'entre eux), à la guerre et à la prospérité matérielle. Cependant, à s'en tenir strictement à la méthode dumézilienne, un schéma de trifonctionnalité implique un groupement homogène, une série explicite, nommée en tant que telle. Il faudrait donc, pour donner corps à notre démonstration, une triade de propositions parallèles ou d'épithètes fonctionnelles accolées, " comparables à celles que plusieurs peuples indo-européens appliquent aux divinités et aux héros dont ils veulent, justement, par opposition à d'autres, spécialisés, souligner le caractère omnivalent ${ }^{3{ }^{34}}$. Or, comme nous l'avions indiqué incidemment en $1979^{\text {t0}}$, une telle séric existe bel et bien dans le mythe de Râto Matsyendranâth. Ce mythe, dont la forme la plus complète est une version néwari datant vraisemblablement $\mathrm{du} \mathrm{XVII}^{\mathrm{e}}-\mathrm{XvIII}^{\mathrm{e}}$ siècle ${ }^{+1}$, précise que Narendradeva partit à la recherche de Karunâmaya accompagné de deux autres personnes : un prêtre bouddhiste Gubhâju du nom de Bandhudatt (son maître 
spirituel, âcârya) et un porteur de la caste des Jyâpu (paysans) appelé Ratna Cakra (ou Lalita Cakra). Ces trois héros symbolisent clairement la prêtrise (ou les valeurs spirituelles), la royauté et la masse des agriculteurs 42. C'est grâce aux efforts conjugués de ces trois " ordres », unis par des liens de services mutuels, que l'expédition put être menée à bien.

Une fois Matsyendranâth introduit dans la vallée du Népal, poursuit le récit mythique, il fut décidé d'organiser une fête en l'honneur du dieu. Le guru Bandhudatt présida à la première fête, le roi Narendradeva à la deuxième, le porteur Jyâpu à la troisième. Quant à la quatrième, elle fut célébrée par les dieux, les démons yakșa, râkșas, bhûta, et le peuple en général. On reviendra sur ce quatrième plan plus avant. Retenons pour l'instant que l'arrivée de Matsyendranâth est attribuée à l'action combinée de trois composantes majeures de la société néwar et que cette synthèse est exprimée selon un schéma d'idées dont on trouve de nombreux équivalents chez les peuples indo-européens.

Mais le mythe va plus loin. Dans un passage ultérieur, le corps du dieu luimême est explicitement mis en relation avec cette trilogie.

Le roi Narendradeva, Bandhudatt et le Jyâpu revinrent ensuite à Swayambhu pour saluer Shantikar Vajracarya (celui-là même qui avait envoyé Narendradeva chercher Matsyendranâth pour mettre fin à la terrible sécheresse) et lui apprendre le succès de leur mission. Après quoi, les trois héros rendirent visite à Lokanâth. Bandhudatt lut une prière qu'il avait composée et demanda au roi d'accomplir une dernière tâche, à savoir le tuer, comme il l'avait juré quelque temps auparavant. Contrairement à toute convenance, le prêtre bouddhiste avait en effet dû réveiller le souverain, une fois lors de leur expédition, en le heurtant du pied, ce qui avait mis le roi dans une grande fureur. Narendradeva tenta d'abord de se dérober. Il finit cependant par accepter de tuer son âcârya de manière symbolique. Une statue de Bandhudatt fut fabriquée et le roi la brisa en deux. Juste avant d'expirer, le prêtre bouddhiste s'incorpora dans le pied droit de Lokanâth. Chagriné, le roi récita un poème de louange qu'il avait composé et passa dans le pied gauche du dieu, atteignant la délivrance, mokșa. Quand Ratna Cakra vit cela, il perdit tout intérêt à la vie. Il mourut lui aussi et passa dans le bassin du dieu ${ }^{\text {th }}$.

Cette formule ternaire apparaît de manière récurrente dans le mythe et organise l'ensemble du récit. Elle donne indiscutablement une dimension trifonctionnelle à Matsyendranâth ; la divinité s'y voit comme tout entière ramassée. Relevons qu'une telle triade est toujours profondément ancrée dans les représentations populaires contemporaines : jusqu'à il y a peu de temps encore, les statues des trois héros étaient ainsi exposées en ligne chaque premier jour du mois solaire devant le temple du dieu à Bungamati - ceci durant les six mois de l'année pendant lesquels Matsyendranâth réside dans ce village ${ }^{44}$.

\section{Un dieu bouddhiste dans un royaume hindou}

Il convient, à ce stade de l'analyse, de faire deux observations.

Cette image trifonctionnelle est tout à fait exceptionnelle dans la culture et l'histoire népalaise. A ma connaissance, c'est le seul cas indiscutable pour 


\section{AUTOUR DU RELIGIEUX}

l'ancienne vallée du Népal de ce que Dumézil a appelé l'idéologie des trois fonctions, le seul où la structuration ne prête pas à contestation. On trouve bien dans la vie rituelle, notamment à propos des prêtres funéraires, certaines séries triadiques ${ }^{45}$, mais leur intention fonctionnelle est beaucoup plus douteuse. Il s'agit donc d'une occurrence limitée, circonscrite à une divinité, Matsyendranâth, et qui requiert par conséquent une explication particulière.

Il est pratiquement impossible, en l'état actuel des connaissances, fort limitées en raison de la rareté des documents, de savoir précisément d'où vient cette notion et d'en reconstituer l'histoire de manière exhaustive. Doit-on y voir une résurgence d'un vieil archétype de pensée indo-européenne ? Peut-être. Mais à supposer que tel soit le cas, cet archétype a été recomposé, remodelé pour des raisons précises et n'a réapparu qu'à une certaine époque, sous la pression de certaines circonstances particulières. C'est dans cette direction que je voudrais mener la recherche et qu'on peut espérer avoir une vue neuve de notre sujet.

Interrogeons-nous tout d'abord sur le contenu social de ce schéma trifonctionnel : un prêtre bouddhiste Gubhâju, un roi, un paysan Jyâpu. S'agit-il d'une image fidèle de la société concrète de l'époque ? Non. La population de la vallée de Kathmandou sous la dynastie Malla était autrement plus complexe que les trois figures du mythe réunies. Elle comprenait en particulier une proportion importante d'artisans et de commerçants qui ont fait la renommée du nepâl mandala en Haute Asie et en Inde. Dans le cas qui nous occupe, ces groupes ont été gommés. La société Malla était par ailleurs traversée par d'autres systèmes de classification : castes pures-castes impures, prêtres bouddhistes-prêtres hindous par exemple, qui n'apparaissent pas ici bien qu'il fussent fréquemment invoqués dans les témoignages qui nous sont parvenus de cette époque. La structuration en quatre varna (à laquelle s'est ajoutée ultérieurement celle en 64 castes, $j \hat{a} t)^{46}$, était par ailleurs elle aussi en usage depuis longue date. Elle semble avoir eu un rôle dans certains rituels ${ }^{47}$ et intervenait dans les codifications juridiques, même si elle s'appliquait parfois mal à la société locale.

Il s'agit donc d'une structure simplifiée qui implique un choix délibéré. Pour comprendre ce choix, il faut remonter dans le temps et se représenter la situation de Patan aux xve-XviII siècles. A l'époque comme aujourd'hui, cette ville était en majorité bouddhiste et comptait plus de 150 monastères de confession mahâyanique. Elle constituait un conservatoire du bouddhisme indien médiéval, maintenant depuis le XIII ${ }^{\mathrm{e}}$ siècle une vie intellectuelle et religieuse qui avait disparu de l'Inde à la suite des invasions musulmanes. Or, les rois Malla de la cité, comme ceux des deux autres petits royaumes de la Vallée (Kathmandou et Bhaktapur), étaient de religion hindoue. Ils étaient couronnés selon des rituels védiques et vivaient entourés de prêtres brâhmaniques qui célébraient les cérémonies du cycle de vie de la famille régnante et avaient un rôle prééminent dans les grands temples de la capitale et la direction spirituelle du royaume. Pour fonder leur autorité, les souverains devaient impérativement se concilier la grande masse de leurs sujets. Tout le culte royal de Matsyendranâth, une figure bouddhiste au départ, ne l'oublions pas, s'explique par cette nécessité politique et culturelle. En faisant de ce dieu leur divinité d'élection, en I'élevant au statut de divinité palatiale, en patronnant sa fête, Siddhinarasimha et son fils Srinivas Malla cherchaient à s'imposer auprès de la population de leur 
royaume et à réunir un consensus autour de leur personne. Le prestige qu'ils tirèrent de cette dévotion généreuse fut considérable. Les habitants de Patan en gardent un souvenir très précis et continuent de considérer ces deux souverains comme des bienfaiteurs particulièrement intentionnés ${ }^{48}$.

La formulation du mythe de Matsyendranâth dans des termes trifonctionnels semble être, elle aussi, liée d'une manière ou d'une autre à l'importance nouvelle que prit ce dieu dans la vie de Patan. En associant à la figure royale un Gubhâju et un Jyâpu, c'est-à-dire un prêtre bouddhiste et un représentant de la très large caste des agriculteurs, bouddhistes eux aussi par confession, le mythe définit un esprit de concorde entre le souverain hindou et la population de la ville. Il symbolise cette allianci.

Notons cependant que ce patronage royal d'une divinité bouddhiste, Karunâmaya, alla de pair avec un processus d'hindouisation. C'est au Xvir ${ }^{\mathrm{e}}$ siècle en effet que les Néwar hindous reconnurent dans Karunâmaya le dieu Matsyendranâth et en firent une de leurs divinités majeures. Nous verrons plus loin que le légendaire Kânphatâ Yogî influença de toute évidence le mythe et le rituel du dieu. Pour l'heure, notons que ce n'est sûrement pas un simple hasard si Siddhinarasimha commit justement à cette période, en 1631 exactement, deux brâhmanes Râjopâdhyâya pour guider le char du dieu pendant la fête de Patan ${ }^{49}$, ouvrant ainsi une brèche dans le monopole total que le clergé bouddhiste exerçait sur le dieu. Ce n'est sans doute pas non plus une simple coïncidence si Srinivas fonda quelques années plus tard une association religieuse pour permettre aux Nâtha Yogî d'accomplir une cérémonie annuelle en l'honneur du dieu à Bungamati ${ }^{{ }_{0}}$. En s'associant de près à Matsyendranâth, ces deux souverains le firent entrer progressivement dans l'orbite hindoue. Le syncrétisme au Népal répond aussi à des préoccupations « politiques » au sens restreint du terme.

Il faut enfin savoir que Patan, rattachée depuis 1482 au royaume de Kathmandou, n'acquit son indépendance qu'à l'avènement de Siddhinarasimha en $1620^{51}$. Elle entra alors très vite en compétition avec les deux cités-États voisins, des royaumes de poche comme le sien, formés d'une petite capitale et d'un arrière-pays agricole microscopique. Les incessantes rivalités concernaient autant le contrôle des routes de commerce transhimalayennes qui passaient à l'époque presque exclusivement par la vallée du Népal et dont les royaumes Malla tiraient l'essentiel de leur richesse, que des querelles de préséance, assez naturelles entre trois branches d'une même famille jalouses de leur indépendance. Or politique et religion étaient totalement liées : le roi gouvernait par la bénédiction d'un ou plusieurs dieux dont il entourait son palais. De sorte qu'en cherchant à donner à Matsyendranâth un rayonnement qui dépassât le strict cadre de Patan, Siddhinarashimha et son fils tentaient aussi de glorifier leur cité et de s'attribuer la suprématie dans le nepâl mandala. Au Népal comme en Inde, la monarchie s'est toujours appuyée sur de telles entreprises de légitimation religieuse. Le pouvoir des rois Malla reposait pour une grande part sur de savantes et prestigieuses mises en scènes rituelles qui, à l'instar de la fête de Matsyendranâth, donnaient à voir à chacun sa place dans la société et accréditaient l'image d'un tout harmonieux placé sous l'autorité d'un souverain. 


\section{AUTOUR DU RELIGIEUX}

\section{Matsyendranâth et l'unité de la vallée du Népal}

Les rivalités et les jalousies entre principautés apparaissent dans le mythe d'origine du dicu. Ce dernier indique en effet que l'arrivée de Matsyendranâth entraîna un conflit entre les trois capitales des royaumes Malla : Patan, Kathmandou et Bhaktapur. Chaque cité voulait Matsyendranâth pour elle et souhaitait l'établir dans ses murs.

Les autres commencèrent à se disputer sur l'endroit où le temple du dieu devait être construit. Le roi Narendradeva estimait que ce devait être Bhaktapur, sa capitale. C'était lui, après tout, qui avait conduit l'expédition au Kamarupa et ramené Matsyendranâth. Le guru (Bandhudatt) pensait, lui, que l'entreprise n'avait abouti que grâce à ses pouvoirs magiques et que le temple devait par conséquent être construit dans sa ville, Kathmandou. Quant au paysan, il plaidait pour Patan, sa cité natale. Comme ils n'arrivaient pas à se mettre d'accord, Bandhudatt suggéra de s'adresser au roi de Patan, Baladeva, et de s'en rernettre au choix de l'homme le plus âgé et le plus sage de cette ville. Tous acceptèrent cette proposition. Mais le Jyâpu s'introduisit secrètement dans sa cité et apprit au roi le parti qui venait d'être décidé. Baladeva courut chez le vieux sage de Patan et le soudoya. Le lendemain, les trois héros se présentèrent devant le roi. Ils lui expliquèrent leurs difficultés. Baladeva les conduisit chez le vieil homme qui, après quelques hésitations, se prononça pour Patan, bien qu'au fond de lui, il était d'avis que Matsyendranâth devait revenir à Bhaktapur, la capitale de Narendradeva. Sitôt sa décision prononcée, le vieil homme tomba mort, foudroyé par sa malhonnêteté. Mais le marché était déjà conclu et le roi Narendradeva s'en tint au choix injuste ${ }^{\varsigma 2}$.

Le mythe met donc très fidèlement en scène le paysage politique de la vallée du Népal au XVII ${ }^{e}$ siècle. Il s'ancre dans les réalités et les enjeux territoriaux de l'époque. Conséquence importante, relevons-la au passage : ce récit n'a pu ctre composé qu'après 1620 , c'est-à-dire après la division effective du nepâl mandala entre les trois royaumes cités. Il comprend peut-être des éléments plus anciens (l'image trifonctionnelle proprement dite ?), reflet d'un état archaïque des représentations religieuses, mais le cadre d'ensemble fait allusion à une situation relativement récente.

La légende d'origine a ici une double fonction. Il s'agit d'abord de justifier le choix de Patan, et de son royaume, pour l'emplacement du temple du dieu. Un choix qui n'est pas toujours à l'honneur de ses habitants (ils ont dû employer la traîtrise pour obtenir ce privilège) et qui n'a pas forcément la logique pour lui : Matsyendranâth, après tout, n'échoit ni à la ville du roi, ni à celle du prêtre, mais à celle du paysan Jyâpu, la figure dont le statut est le plus bas dans la série tripartie. Le dieu revient donc à Patan, mais dans un contexte élargi où se trouvent impliqués les deux royaumes voisins. C'est précisément là la seconde fonction du mythe : donner à Matsyendranâth une dimension suprarégionale qui transcende la fragmentation du nepâl mandala, qui en exprime l'unité profonde, réelle au demeurant, au-delà des rivalités politiques. Tout le mythe finalement s'organise autour de ce double thème : unité et division. Patan est choisi, mais les trois premières fêtes du dieu sont patronnées à tour de 
rôle par les trois capitales. Matsyendranâth, ce dieu à multiples facettes, est là pour concilier les forces centrifuges et centripètes qui tiraillent alternativement les structures politiques de la vallée du Népal.

Cette ambition transparaît encore nettement dans le rituel festif contemporain. Au cours de ses pérégrinations autour de Patan, le char doit passer principalement par trois points principaux : Gabaha à l'ouest, Sundhara à l'est et Lagankhel au sud. Or un vieux dicton indique que la fête de Gabaha est réservée aux habitants de Kathmandou, celle de Sundhara aux habitants de Bhaktapur et celle de Lagankhel aux habitants de Patan. Quant à l'exposition de la chemise du dieu à Jaulakhel, le dernier jour des festivités, elle appartiendrait aux habitants du monde entier ${ }^{53}$. Le dicton est démenti par les faits : les trois premières fêtes ne rassemblent en réalité que les habitants de Patan. Il est cependant révélateur quant à la signification profonde du dieu fêté.

Les anciennes dissensions ne sont pas oblitérées pour autant. Ainsi, si le char, pour une raison ou pour une autre, ne parvient pas à temps à Jaulakhel, les habitants de Bhaktapur sont en droit de réclamer que le dieu soit transféré dans leur ville et y soit gardé sine die. Un tel cas se serait produit à la fin du $\mathrm{XIX}^{\mathrm{e}}$ siècle ${ }^{54}$. Le motif est transparent : si les habitants de Patan ne sont pas en mesure d'accomplir correctement le rituel festif, comme ils s'y étaient implicitement engagés en installant le dieu chez eux, la vieille rivalité Patan-Bhaktapur resurgit et la revendication de la ville du roi Narendradeva redevient d'actualité.

L'aspect trivalent du dieu Matsyendranâth s'accompagne donc d'une tripartition territoriale qui n'a, au départ, rien à voir avec la tripartition fonctionnelle, mais à laquelle les circonstances historiques locales ont donné une valeur essentielle. Matsyendranâth n'exprime pas seulement l'unité du corps social, il témoigne aussi de l'unité d'une région culturelle et politique homogène, quoique segmentée en royaumes mitoyens et rivaux.

\section{Matsyendranâth et les fondements de la royauté}

Il est temps maintenant de revenir au tout début du mythe, cité d'après la même version.

C'est à un chacal blanc, une manifestation du dieu Nârâyan, que lc roi Gunakâmadeva maria sa fille. Peu de temps après, ce dieu apparut à son beaupère. En cadeau, il lui donna du riz, plante qui à l'époque n'existait pas encore au Népal. Le riz fut semé, mais au moment de la récolte, les balles de la plante restèrent vides. Nârâyan intervint à nouveau. Il prédit que le dieu du grain, Padma Arya Avalokiteçvara, son guru, viendrait un jour au Népal et remplirait la balle avec du grain. Il confia également à son beau-père que Karunâmaya vivait pour l'heure sous une apparence humaine à Kamuni et qu'il arriverait au Népal sous le règne de son fils. Nârâyan enjoignit Gunakâmadeva de se consacrer aux œuvres religieuses et de faire preuve de piété. Après quoi, il disparut. Le roi suivit les recommandations de Nârâyan à la lettre ; il mena une vie exemplaire placée sous le signe de la religion. Sa conduite méritoire ne resta pas sans effet : un fils lui fut donné, Narendradeva. Quand il sentit le moment venir, le vieux roi fit couronner son héritier et partit vers la forêt finir ses jours dans la solitude ":. 


\section{AUTOUR DU RELIGIEUX}

Nous avons déjà fait allusion à Matsyendranâth, dieu du riz, introducteur de cette plante dans la vallée du Népal. Mais une lecture plus approfondie du texte peut être tentée. De quoi s'agit-il en fait dans ce passage ? D'un mariage entre deux lignées : d'une part celle du roi Gunakâmadeva et son fils Narendradeva, de l'autre celle du chacal blanc Nârâyan. La première représente, c'est l'évidence, le pouvoir royal. Mais la seconde ? La figure centrale parait être ici le chacal et non Nârâyan, car en contexte hindou, tout gendre d'une personne de haute caste est assimilé à ce dieu. Qui est alors le chacal blanc ? L'important, à mon sens, tient à ce que cet animal donne au maître du pays le riz, certes sans grain aucun dans l'épi, mais plante vitale tout de même, sans laquelle la prospérité de la vallée serait inévitablement compromise. Je suggère d'y voir, face à la maison royale, d'origine indienne, une allusion à la population agricole originaire de la vallée du Népal, c'est-à-dire au socle ethnique néwar le plus ancien, marqué par des traits sino-tibétains ${ }^{56}$. Autorité royale d'un côté, autochtonie de l'autre : tels paraissent être les deux éléments en présence.

Si cette hypothèse est juste, le mythe de Matsyendranâth prend une dimension nouvelle. En plus de tout ce qui a déjà été dit, il symboliserait aussi une alliance très ancienne, fondatrice en quelque sorte, entre une population locale indigène, ancêtre des agriculteurs Jyâpu d'aujourd'hui, et une dynastie conquérante d'origine étrangère. Quoique traduite dans un langage mythique propre, le début du récit renverrait à la conquête, rapportée par les chroniques, de la vallée du Népal au début de l'ère chrétienne par des populations indiennes et à leur mélange avec l'ethnie indigène. Tout se passe donc comme si la formule tripartie cachait une autre configuration, binaire celle-là, opposant les élites dirigeantes, prêtres et roi, à la grande masse (agricole) de la population.

Il est intéressant à cet égard de savoir que les agriculteurs Jyâpu ont un rôle rituel important dans le culte des grandes divinités gardiennes du royaume. Dans la plupart des temples actuels de la vallée du Népal, l'équipe de desservants attachée à la divinité comprend en effet un ou plusieurs Jyâpu et leurs femmes. Ce ou ces couples Jyâpu sont cantonnés dans un rôle de service (approvisionnement en fleurs et en grain, nettoyage de l'aire sacrée) et d'auxiliaires rituels, mais leur présence est nécessaire au bon fonctionnement du temple, et jusqu'à un certain point, aux cérémonies qui s'y déroulent. Ces dispositions, qui sont assorties de droits sur le revenu de certaines terres à vocation religieuse, datent toutes de l'époque Malla. En faisant participer les Jyâpu (et d'autres castes de service avec eux) à leur entretien et à leur culte, les temples fonctionnaient comme des espaces modèles : ils illustraient aux yeux de tous la nécessaire collaboration de plusieurs groupes hiérarchisés à l'accomplissement de la vie religieuse. Comme les grandes fêtes auxquelles ils étaient souvent liés, ces espaces sacrés cristallisaient un ordre symbolique supérieur et proposaient aux sujets du royaume l'image d'un monde exemplaire trouvant son fondement ultime dans l'armature invisible de l'univers.

Revenons au mythe de Matsyendranâth. Pour sceller le pacte entre la famille royale et la population autochtone, il fallait un médiateur. A elle seule, l'alliance entre le fils du roi et le chacal ne suffit pas : elle ne produit que des épis vides. C'est Matsyendranâth, une divinité extérieure à la Vallée, qui va jouer ce rôle intermédiaire. C'est lui qui va concilier les deux groupes représentant l'un la force physique et la souveraineté, l'autre la richesse matérielle et la 
terre. La légende de Matsyendranâth mérite de ce point de vue d'être considérée comme un mythe d'origine de la royauté de la vallée du Népal, un discours sur les fondements d'un royaume multi-ethnique réconcilié.

Arrivée à ce point de la recherche, il convient de mentionner l'influence probable du nâthisme. Les liens entre les rois Malla et Matsyendranâth évoquent en effet les relations si particulières qui existaient à Gorkha, un royaume de l'ouest népalais, entre la dynastie régnante Shah et sa divinité tutélaire Gorakhnâth - disciple de Matsyendranâth dans le légendaire propre aux Kânphatâ Yogî. Comme Matsyendranâth à Patan, Gorakhnâth fut promu iștadevatâ, divinité d'élection des souverains Shah. Ce dieu était l'inspirateur et le garant du royaume ${ }^{57}$. Ses apparitions et ses interventions multiples étaient jugées, elles aussi, décisives pour le roi et avaient une valeur prophétique pour le royaume tout entier. C'est grâce à Gorakhnâth et à ses desservants Kânphatâ Yogî, que, dit-on, Prithivi Narayan parvint à unifier le Népal à la fin du XviI ${ }^{\mathrm{e}}$ siècle. Il est vraisemblable que dès avant la conquête des royaumes Malla au XviII ${ }^{\mathrm{e}}$ siècle, les Kânphatâ influèrent sur Matsyendranâth et prirent une part dans la formulation, ou plus exactement la reformulation, de son mythe d'origine ${ }^{58}$.

Ce parallèle entre le royaume de Gorkha et ceux de la vallée du Népal mérite d'être poursuivi. Toutes ces principautés attribuaient, surtout après le XVIII $^{\mathrm{e}}$ siècle, une place éminente à des Nâth, ici Gorakhnâth, là Matsyendranâth, parmi les divinités royales. Mais alors qu'à Gorkha les desservants de Gorakhnâth sont des Kânphatâ Yogî, dans le royaume de Patan ceux de Matsyendranâth sont des bouddhistes. Il n'y a là rien de surprenant : à la différence de ce qui s'est passé dans les collines de l'ouest (caubisi râjya), les royaumes de la Vallée ont dû composer dès leur création avec une communauté bouddhiste aussi nombreuse qu'influente. Comme les Kânphatâ, les prêtres bouddhistes mettent leurs pouvoirs extraordinaires, obtenus grâce à des exercices spirituels et à des initiations tantriques compliquées, au service du roi et prennent en charge la même dimension obscure de la religion. Comment par ailleurs ne pas rapprocher le couple Bandhudatt - Narendradeva de la paire Bhagavantanâth (un célèbre Kânphatâ protégé par le roi) - Prithivi Narayan ? Ici comme là, c'est la conjonction d'un pouvoir spirituel d'essence magique et d'un pouvoir royal qui permet d'éloigner les obstacles et d'imposer une souveraineté nouvellement conquise. En mettant en scène un prêtre bouddhiste, et non un brâhmane, le mythe de Matsyendranâth ne fait que refléter une réalité objective et renvoyer à une conception de la monarchie largement répandue dans les royaumes hindous de l'Himalaya.

Les implications sont nettes : le roi est la clef de voûte, l'élément central du culte de ce dieu. La fonction qu'il incarne a joué un rôle décisif dans la consécration et l'instauration de cette figure divine. C'est sous son autorité et son contrôle que le Vajrayâna, le folklore néwar et le culte des Nâth, se sont superposés et soudés les uns aux autres pour aboutir au Matsyendranâth que nous connaissons aujourd'hui. Il est l'artisan, appliqué et intéressé, de ce syncrétisme complexe.

Il y a plus. A l'instar de Matsyendranâth, son double, le roi focalise les différents composants de la société, il en fait la synthèse dans sa personne. Entre le dieu et le roi, l'identité est totale. Le souverain, à titre d'exemple, est autant le responsable, le garant de la prospérité matérielle que Matsyendranâth. Comme 


\section{AUTOUR DU RELIGIEUX}

ce dernier, il a des affinités avec la pluie. Comme lui, il est l'arbitre de l'ordre social et tient réunis les groupes sociaux ${ }^{59}$. D'une certaine manière, la fortune du schéma triparti dans le mythe du dieu et le futur du pouvoir royal sont liés. Le mythe fonctionne pour l'essentiel au profit de la royauté.

Ce pouvoir n'est cependant pas illimité, il reste subordonné à des principes religieux supérieurs, sur lesquels le roi peut agir mais qui conservent leur autonomie. Le souverain a besoin de s'attacher des divinités avec lesquelles il entretient des rapports ambivalents de protecteur et de protégé, de la même manière qu'il reste toute sa vie dépendant de la caste sacerdotale (représentant les dieux) qui le domine d'un point de vue du statut. Sa marge de manœuvre est restreinte. Son pouvoir n'est efficace et ne devient légitime que par l'intermédiaire de puissances divines : Matsyendranâth tout autant que Taleju et Paçupatinâth ${ }^{60}$. Le royaume tout entier s'ordonne à partir d'une relation aux dieux, dont la mise en scène ritualisée a pour cadre les temples et les grandes cérémonies festives.

\section{Une quatrième fonction?}

N. J. Allen, un spécialiste des religions du Népal, a suggéré récemment l'existence d'une quatrième fonction dans le mythe et le culte de Matsyendranâth ${ }^{61}$. Il range dans cette quatrième fonction (baptisée F4) tous les aspects troubles, incontrôlés, impurs de ce dieu : son ascendance démoniaque (dans certaines versions, la mère de Matsyendranâth est elle-même une sorcière dâkinîl ; les simulacres érotiques auxquels se livrent les femmes de pêcheurs Pode, une caste impure, sous le char du dieu, quand ce dernier traverse leur quartier ; la possession des femmes de prêtres bouddhistes pânju pendant la fête de Jaulakhel ; la colline Mhaipi, réputée pour ses sabbats de sorcières, dont on extrait la terre pour fabriquer la statue du dieu, etc. Cette figure divine comporterait donc une dimension obscure, " liée aux intouchables, aux fantômes et aux sorcières $\rangle^{62}$ et renverrait à un état ancien, préhindou, de la religion.

Le culte de Matsyendranâth se caractériserait également, selon cet auteur, par de nombreux traits chamaniques que viendrait éclairer une analyse comparative portant sur d'autres populations tibéto-birmanes ; en particulier les Thulung du Népal oriental. Allen propose par exemple de voir en Bandhudatt un chamane flanqué d'un assistant, Narendradeva, et d'un esprit auxiliaire, le dieu serpent Kârkotaka ${ }^{63}$. S'opposant au modèle sacrificiel hindou que j'avais suggéré autrefois ${ }^{\text {fit }}$, il interprète la légende de Matsyendranâth comme un voyage mythique dans l'au-delà semé d'embûches et de dangers. Cet itinéraire serait bâti sur la même structure conceptuelle que les voyages rituels dont il fait une des particularités des religions himalayennes.

Une remarque d'ordre général s'impose ici : l'histoire des religions s'est toujours perdue à porter une attention trop soutenue aux questions des origines. Les figures de l'archaïsme sont trop séduisantes pour ne pas être trompeuses. Reportons-nous aux aspects magiques de Matsyendranâth, à ses affinités avec les forces chthoniennes. Allen explique ces traits par des aspects tribaux relevant d'une vieille "idéologie segmentaire " ${ }^{65}$. Mais il n'est pas nécessaire d'aller chercher si loin : le cadre indien fournit de nombreux parallèles. En fait, dans la tradition Kânphatâ Yogî (ou Nâtha Yogî), certains 
membres de la secte sont crédités de pouvoirs mystiques supra-normaux (siddhi) : ils peuvent guérir les malades, ressusciter les morts, faire tomber la pluie, etc. La philosophie de ce courant sectaire impose explicitement à ceux de ses initiés qui sont parvenus aux plus hauts degrés de réalisation spirituelle la recherche de tels pouvoirs extraordinaires conçus comme une victoire sur le temps ${ }^{66}$.

Les aspects liés à la fertilité et aux plantes nourricières ne peuvent, eux non plus, être rattachés exclusivement à un fonds tribal tibéto-birman. Des faits semblables se retrouvent au Kumaon et dans d'autres régions du Népal, en particulier dans l'extrême-ouest, où le substrat tribal tibéto-birman est pratiquement inexistant. Comme Matsyendranâth dans la vallée de Kathmandou, le héros déifié Candannâth, expert ès-sciences magiques, est censé avoir introduit le premier grain de riz dans la vallée de Jumla ${ }^{67}$, et à Dewalgarh (au Kumaon) on dit que durant l'ère du Satyayuga, Satyanâth, un autre héros Kânphatâ Yogî, était représenté par un grain de blé enveloppé dans de l'or et posé sur un trône à l'intérieur d'un temple ${ }^{68}$. Ces éléments sont directement à mettre au compte des Kânphatâ Yogî qui associent souvent la fondation d'un royaume aux exploits supra-humains d'un de leurs ancêtres héroïques. Sont-ils plus spécifiques de l'Himalaya que de l'Inde proprement dite ? Difficile de trancher. Il serait cependant erroné de les rapporter à un seul substrat tibéto-birman car l'héritage culturel indo-européen de l'Himalaya en est aussi marqué. Les faits, on le voit, sont complexes : l'arc himalayen a toujours été un carrefour d'idées, un lieu de brassage de peuples et de civilisations.

Mais revenons à la quatrième fonction. Pour Allen, la série trifonctionnelle que nous avons relevée serait plutôt une tétrade. "Seuls trois hommes entreprennent le voyage, mais la participation de Kârkotaka le Nâg est essentielle à son succès " ${ }^{69}$. "La statue de Matsyendranâth ne contient pas seulement la triade qui s'incorpore à elle, mais aussi les os réduits en cendres du fils de Çantikar $"{ }^{70}$. De même, y a-t-il quatre fêtes et non trois, la quatrième étant organisée, on s'en souvient, par des êtres démoniaques, des dieux et des hommes. Ces arguments ne paraissent pas très convaincants. D'abord parce que, sauf dans le cas de la fête du dieu, le quatrième terme n'est nulle part intégré à une série, comme le réclame Dumézil, et qu'on n'y sent jamais une intention fonctionnelle organisatrice comme pour les trois premiers. Ensuite, à y regarder de plus près, cette quatrième fonction apparaît particulièrement vague et ambiguë. Elle inclut des êtres fort dissemblables, le même et son contraire, tout ce qui finalement n'est pas compris dans les trois premiers termes. Il s'ensuit que cette fonction est hétérogène par rapport aux trois premières et qu'elle peut difficilement être placée sur le même plan. En vérité, comme Charles Malamoud l'a fait remarquer dans un article sur la signification du chiffre 4 dans la pensée brahmanique, le quatrième terme d'une série de trois n'a pas, en contexte indien, le même rang ni la même valeur que ceux qui le précèdent ${ }^{11}$. Cet élément supplémentaire est là pour transcender les premiers, les englober, en exprimer la quintessence, ou bien ouvrir sur l'infini, en introduisant l'au-delà, alors que justement les trois fonctions constituent des ensembles perceptibles et finis. Le passage d'une triade à une tétrade n'entraîne donc pas automatiquement une rupture à l'intérieur des contraintes internes du système : il peut signifier - l'exemple étudié ici le montre amplement - un élargisse- 


\section{AUTOUR DU RELIGIEUX}

ment et un enrichissement de la structure trifonctionnelle ${ }^{72}$. Allen, rendons-lui justice, reconnaît que cette quatrième fonction est plus abstraite que les trois premières, qu'elle possède un caractère particulier (apartness) et qu'elle ne correspond jamais à un métier ou à une fonction sociale. «F4, écrit-il, n'est pas autosuffisante, mais relationnelle $"{ }^{73}$. Pourquoi alors la placer sur le même registre que les autres ${ }^{74}$ ? A la limite, F4 n'est pas une fonction au même titre que les trois premières, mais un terme à contenu variable, défini différemment selon les cultures qui y ont recours.

\section{Les dieux, instrument du pouvoir royal?}

En s'intéressant principalement au fonds de croyances le plus ancien des Indo-Européens, Dumézil n'a-t-il pas négligé les modes de transmission et les contextes historiques particuliers ? La question, on le sait, a été posée ${ }^{75}$. A propos du schéma trifonctionnel, Lévi-Strauss parle par exemple de « forme vide » remplie à chaque époque de contenus différents ${ }^{76}$. Bien qu'il ne se soit jamais totalement laissé enfermer dans les seuls noyaux archaïques et qu'il n'ait jamais été tenté par une analyse phénoménologique des faits religieux, Dumézil s'est peu préoccupé de mutations historiques. Ses livres laissent sans réponse la question de savoir quels rapports existent, au sein d'une culture donnée, entre les modèles idéologiques archaïques de type trifonctionnel et les nécessités concrètes de l'histoire.

Nous ne saurons jamais avec certitude si le schéma triparti qui organise le mythe de Matsyendranâth était hérité de la nuit des temps ou s'il fut construit de toutes pièces à la fin de la période Malla. On peut cependant affirmer, en reprenant les termes de Georges Duby à propos du Moyen Age occidental, que même s'il s'agit d'une « structure latente qui échappe à l'histoire, les systèmes dont ce schéma trifonctionnel forme l'une des membrures appartiennent incontestablement, eux, à l'histoire " ${ }^{77}$. Les idées religieuses ont beau s'incarner d'une manière quasi permanente au cours des siècles, elles n'en resurgissent pas moins avec plus ou moins de force à des moments particuliers. Au XVII ${ }^{e}$ siècle, le cas de configuration trifonctionnelle de Matsyendranâth naît de circonstances dans la société réelle. Il met en scène un contexte social et territorial concret, il traduit des influences religieuses précises, il a un sens donné aux yeux des souverains et de leurs sujets.

L’excmple de Matsyendranâth analysé ici prouve également qu'un tel cadre de pensée peut être utilisé à des fins politico-culturelles. Associé à d'autres éléments omnivalents, le mécanisme des trois fonctions a très probablement été employé dans le Népal du XVII ${ }^{\mathrm{e}}$ siècle pour cimenter l'unité religieuse et ethnique d'une région et renforcer le contrôle d'un souverain sur ses sujets. Certes, les relations de causalité ne sont pas simples : nous sommes devant une situation complexe, ambiguë dans laquelle le pouvoir politique reste, du moins en théorie, subordonné aux valeurs religieuses. Certes, le récit d'origine de Matsyendranâth, qui a eu plusieurs formulations successives, et donc plusieurs auteurs, devait être tenu, comme il l'est aujourd'hui, pour un conte invérifiable par la grande masse de la population. Il n'empêche que le mythe et l'ensemble festif qui le sous-tend imposent l'idée selon laquelle l'ordre socio-cosmique 
repose sur le bon fonctionnement de trois grandes fonctions sociales : la prêtrise, la royauté et le travail agricole, hiérarchiquement définies et non interchangeables. Le schéma trifonctionnel ne peut donc être entièrement réduit à un système de représentations autonome, métasocial, évoluant de sa vie propre. Il fonctionne aussi comme une idéologie, au sens de légitimation du pouvoir des couches dominantes de la société ${ }^{78}$. Sa portée n'est pas seulement expressive, limitée par des notions religieuses, intangibles, et respectées par tous, y compris par le roi ; elle a aussi une valeur instrumentale, efficiente du point de vue de l'exercice du pouvoir ${ }^{79}$.

J'ai essayé de montrer il y a quelques années comment les rois Malla donnaient souvent l'impression, à lire les chroniques, de n'être que des instruments entre les mains des grands dieux du royaume ${ }^{80}$. Mais ne peut-on pas renverser la proposition et affirmer, sans pour autant se contredire, que les dieux euxmêmes étaient, d'une certaine manière, des instruments entre les mains des souverains? La question mérite d'être posée car les rois de l'époque étaient parfois des hommes d'une grande personnalité et détenaient un pouvoir non négligeable. Les donations qu'ils faisaient aux temples et à leurs prêtres, les privilèges qu'ils pouvaient accorder à telle ou telle catégorie de leurs sujets, leur donnaient un rôle politique réel ; peu de domaines échappaient à leur influence directe ou indirecte. Les relations étaient donc loin d'être unilatérales : entre le roi et ses divinités tutélaires, l'interdépendance était totale et la confirmation réciproque. D'un côté, les valeurs religieuses conditionnaient le pouvoir ; de l'autre, les pratiques politiques manipulaient les symboles. Les deux aspects étaient comme l'avers et le revers d'une même médaille. C'est ensemble qu'il faut les penser.

On peut aussi s'interroger, d'une manière plus générale, sur le rôle des figures trivalentes (ou multivalentes) que Dumézil a dégagées dans divers panthéons indo-européens. Nul doute que ces dieux répondent eux-aussi à des besoins particuliers qu'il conviendrait de définir, dans la mesure du possible, pour chaque aire géographique. Il faut remarquer à cet égard que de telles divinités, à la fois synthétiques et syncrétiques, ont souvent un lien privilégié avec la fonction royale. L'homologie entre le souverain Malla et Matsyendranâth est une des clefs de la fortune exceptionnelle de ce dieu - comme dans bien d'autres cas sans doute. Ainsi que l'avait suggéré Hocart dans son livre sur la royauté ${ }^{81}$, on peut penser que l'émergence de grandes divinités omnivalentes doit presque partout être mise en rapport avec la figure centrale d'un roi. Mais seule la réunion de plusieurs compétences permettrait de vérifier cette hypothèse et d'en saisir toutes les implications. 


\section{AUTOUR DU RELIGIEUX}

\section{NOTES}

1. Daniel Dubuisson, "Trois thèses sur le Ramayana », Annales ESC, 1979, 3, pp. 464-489.

2. Le sujet a cependant fait couler beaucoup d'encre. Pour une critique des thèses duméziliennes appliquées à la religjon védique, voir M. Gonda, The Dual Deities in the Religion of the Veda, 1972, ct Triads in the Veda (Verhandelingen de l'Académic hollandaise, N. R., 91), 1976. Dumézil a répondu à son détracteur dans "Les trois fonctions vues par M. Gonda ", Appendice III de Les dieux souverains des Indo-Européens, Paris, Gallimard, 1986, troisième édition corrigée. Des jugements plus positifs sur le travail védique de Dumézil ont été portés par Jean NaUdoc, "L'analyse ternaire de la nature dans la pensée indienne ", Revue d'Histoire des Religions, 1980, $\mathrm{n}^{\circ} 1$, pp. 7-26, ct Charles Malamoud, "Les Indo-Européens, les femmes et les chemins de la liberté ", Le Temps de la Réflexion, 1980, $\mathrm{n}^{\circ}$ 1, notamment p. 445. Dans "Structure sociale et structure idéologique : l'apport de Georges Dumézil », dans Georges Dumézil, Cahiers pour un temps, Paris, Centre Georges Pompidou-Pandora Éditions, 1981, p. 154, Daniel Dubuisson a fait quelques critiques sur la fonction sacerdotale (peu marquée en fait) attribuée par Dumézil au couple Mitra-Varuna.

3. Par exemple dans Apollon sonore et autres essais. Esquisses de mythologie, Paris, Gallimard, 1982, p. 44. Commentaire de D. Dubuisson dans " Matériaux pour une typologie des structures trifonctionnelles ", L'Homme, 93, 1985, p. $114:$ " La présence d'un quatrième terme dans la pensée védique n'a pas entraîné la création d'un système idéologique quadrifonctionnel ; étant extérieur au système traditionnel, le Çûdra n'en a pas modifié l'architecture interne ; il est resté l'autre par rapport auquel la hićrarchie se pense cllc-même ". Voir aussi le point de vue assez proche de Louis Dumont, Homo hierarchicus. Essai sur le système des castes, Paris, Gallimard, 1966, pp. 94-95.

4. L. Renot, La civilisation de l'Inde ancienne, Paris, Flammarion, 1986 (1're édition, 1959, p. 59).

5. A ce sujet, voir Madeleine Biardeau, L'Homme, 1978, 1-2, pp. 208-214, dans un compte rendu d'un livre d'Alf Hiltebetcil : le point de vue dumézilien projetterait sur l'Inde des catégories mentales qui lui sont étrangères (p. 211). Dumézil a reconnu ce déplacement dans la pensée indienne, Mythe et épopée, III, Paris, Gallimard, 1978, $2^{\circ}$ édition corrigée, p. 355, mais n’a pas jugé qu'il remettait en question sa théorie générale.

6. Georges DumézIL, La religion romaine archaïque, Paris, Payot, $2^{\mathrm{e}}$ édition corrigée, 1974, pp. 307-308, avec équivalents pour la vieille religion iranienne. Voir aussi Les dieux souverains des Indo-Européens , op. cit., p. 50 ; et pour la déesse trivalente iranienne, Mythe et épopée l, Paris, Gallimard, 1971, pp. 104-105.

7. G. DumÉzIL, La religion romaine archaïque, op. cit., p. 308, et Mythe et Épopée I, op. cit., pp. 103 ss.

8. G. Dumf́z.li., Les dieux souverains des Indo-Européens, op. cit., p. 215. Dans ce même texte, Dumézil écrit : "Il arrive qu'un poète du Rig Veda, par une dévotion particulière sans doute, ou par l'entraînement d'une circonstance que nous ne connaîtrons jamais, veuille attribuer l'omnivalence à une divinité, qui, normalement, n'a qu'une compétence limitée. De tels cas ne sont pas aussi nombreux qu'on pourrait l'attendre dans une religion déjà sensible à ce que sera la grande tentation de l'Inde classique, la confusion des dieux multiples au profit de la Divinité, représentée essentiellement par l'un d'eux. Mais il en est d'incontestables et l'omnivalence peut alors s'exprimer comme dans les cas précédemment signalés, par référence aux trois fonctions, avec ou sans prolongements », p. 219.

\section{Id., pp. 220-222.}

10. D. Dubuisson, « Matériaux pour une typologie des structures trifonctionnelles », op. cit., pp. 110-111, et " Le roi indo-européen et la synthèse des trois fonctions ", Annales ESC, 1978, 1, pp. 21-34. Idée reprise par DumÉzıL, La courtisane et les seigneurs colorés, Paris, Gallimard, 1983, p. 38 .

11. Les Néwar forment aujourd'hui un groupe de quelque 800000 individus (?), dont la moitié vit encore dans la vallée de Kathmandou, leur centre d'origine. Le reste a migré dans d'autres régions du Népal. Sur l'ethnographie et l'héritage culturel de cette population, voir G. S. NePAli, 
The Newars, an Ethno-Sociological Study of a Himalayan Community, Bombay, United Asia Publications, 1965, et G. Toffin, Société et religion chez les Néwar du Népal, Paris, Éditions du CNRS, 1984.

12. Le mot néwar proprement dit n'apparaît dans les sources historiques qu'à partir du $\mathrm{XVII}{ }^{\mathrm{e}}$ siècle.

13. Sur Matsyendranâth et son culte, les sources de base sont M. S. Sulsser, Nepal Mandala. A Cultural Study of the Kathmandu Valley, Princeton, Princeton University Press, 1982, pp. 367379, et surtout J. K. LoCKE, Karunamaya. The Cult of Avalokiteçvara-Matsyendranâth in the Valley of Nepal, Kathmandu, Sahayogi Prakashan, 1980.

14. D. VajRacarya, K. P. Malla, The Gopâlarâjavamçâvalî, Kathmandu, Franz Steiner Verlag Wiesbaden, 1985, p. 126. Cf., aussi LocKe, op. cil., 1980, p. 280.

15. S. LÉvi, Le Népal. Étude historique d'un royaume hindou, Paris, E. Leroux, 1905-1909, vol. 1, p. 353, et A. VERGATI, « Le roi faiseur de pluie. Une nouvelle version de la légende d'Avalokiteçvara Rouge au Népal ", Bulletin de l'École française d'Extrême-Orient, t. LXXIV, 1985, p. 288.

16. LOCKE, op. cit., 1980, p. 300.

17. C'est en particulier la thèse de Locke, op. cit., 1980.

18. Matsyendranâth conjugue en effet principe masculin et principe féminin. Juste avant son bain rituel du mois de Baiçâkh (avril-mai), ses prêtres l'initient aux dix cérémonies, das karma, du cours de la vie, qu'un Néwar de haute caste doit célébrer de son vivant. A cette occasion, un rite de confinement en relation avec les premières règles est célébré. Lorsque la statue de Matsyendranâth retourne à Bungamati après la fête de Patan, les Néwar disent par ailleurs que le dieu rentre dans sa mâiti, mot népali qui désigne la maison natale pour une femme mariée. De plus, les quatre I.okanâth de la vallée de Kathmandou (ceux de Patan, Bungamati, Chobar et Nala) sont qualifiés de « quatre sœurs "; cf. LocKE, op. cit., 1980, p. 345.

19. Vergati, op. cit., p. 289, citant M. Th. Mallmann, Introduction à l'étude d'A valokiteçvara, Paris, PUF, 1967.

20. « Matsyendranâth vient de l'Inde. Cependant son nom ne figure pas dans le panthéon brahmanique ou bouddhique de l'Inde ; mais il se rencontre dans la tradition d'une secte mystique (les Kânphatâ Yogî), où il brille même aux premiers rangs ", S. LÉV1, op. cit., vol. 1, p. 354. Sur l'importance des Kânphatâ Yogî dans l'histoire religieuse du Népal, cf. S. LÉvi, op. cit., vol. 1, pp. 354-358 et G. UNBESCHEID, Kânphatâ. Untersuchungen zu Kult, Mythologie und Geschichte Sivaitischer Tantriker in Nepal, Wiesbaden, Franz Steiner Verlag, 1980. Voir aussi V. BoulLLIER, "La caste sectaire des Kânphatâ Jogî dans le royaume du Népal : l'exemple de Gorkhâ ", Bulletin de l'École française d'Extrême-Orient, t. LXXV, 1986, pp. 125-167.

21. Cf. Slusser, op. cil., p. 369. J. K. Locke cite d'autres textes de la seconde moitié du xvII ${ }^{e}$ siècle, mais on ne sait pas très bien si le Matsyendranâth qui y est cité est le même qu'Avalokiteçvara-Bumga dya (1980, op. cit., p. 327).

22. D. SECKel, L'art du bouddhisme. Devenir, migration et transformation, Paris, Albin Michel, 1964, p. 43, à propos du Cambodge, et L. PeteCH, Mediaeval History of Nepal, Rome, Ismeo, 1958, p. 108, à propos du roi Ripu Malla des royaumes de l'ouest népalais. Au Tibet, le premier roi avéré historiquement, Sron-bcan sgam-po, est lui-même conçu comme une émanation d'Avalokiteçvara ; cf. A. M. Blondfau, "Les religions du Tibet ", dans Histoire des Religions, III, Paris, Gallimard, 1976, p. 249.

23. LoCKE, op. cit., 1980, p. 319 et S. LÉVI, op. cit., 1905, vol. 1, p. 352.

24. LOCKE, op. cit., 1980, p. 308.

25. LOCKE, op. cit., 1980, pp. 316-317.

26. Id., p. 313.

27. Id., p. 303 (d'après une chronique récente, écrite en népali).

28. Sur ces divinités, voir G. Toffin, "Rois dévots et divinités souveraines dans l'ancien royaume de la vallée du Népal », L'Homme, 1986, XXVI, n 3, pp. 71-95.

29. Analyse détaillée de cette inscription dans Locke, op. cit., 1980, pp. 309-310. La responsabilité personnelle du roi envers le dicu y est clairement soulignée. 


\section{AUTOUR DU RELIGIEUX}

30. SLUSSER, op. cit., p. 372.

31. LOCKE, op. cit., 1980, p. 317. Signalons que le pouvoir royal fut associé au culte de Matsyendranâth dès l'introduction de ce dieu dans la Vallée. La Gopâlarâjavamçâvalî signale par exemple qu'au $I^{\mathbf{c}}$ siècle, le roi Balarjunadeva fit don de sa propre couronne à Çrî BugmaLokeçvara ; cf. VAJRACARYA et MALLA, op. cit., p. 126. Au XIVe siècle, les rois Malla se rendaient par ailleurs fréquemment à Bungamati pour vénérer le dieu; cf. LocKE, op. cit., 1980, p. 301.

32. LoCKe, Rato Matsyendranâth of Patan and Bungamati, Kirtipur, Institute of Nepal and Asian Studies, 1973, p. 46.

33. Par exemple G. S. NePali, op. cit., p. 320.

34. La version néwari (une des plus complète et des plus riches) du mythe de Matsyendranâth a été publiée par Asakaji VAJRACARYA, Bungadya Nepâle Hagu Khan, Patan, 2024 BS. Traduction résumée dans J. K. LoCKE, op. cit., 1973, pp. 41-48. Sauf exception, c'est sur cette version que je m'appuie ici. Sur Matsyendranâth : dieu du riz dans les villages néwar d'aujourd'hui, cf. G. Tofrin, Pyangaon, une communauté néwar de la vallée de Kathmandou. La vie matérielle, Paris, Éditions du CNRS, 1977, p. 80.

35. LOCKE, op. cil., 1973, p. 28.

36. Nepali, op. cit., p. 310.

37. S. Lienhard, "Problèmes du syncrétisme religieux au Népal », Bulletin de l'École française d'Extrême-Orient, t. LXV, fasc. 1, 1978, p. 253. En fait, si la graphic est la même, les Néwar font une distinction phonétique entre ces deux mots.

38. LOCKe, op. cil., 1973, p. 35.

39. G. DumÉzII, Mythe et épopée III, op. cit., p. 344.

40. G. Tofrin, "Les aspects religieux de la royauté néwar au Népal ", Archives de Sciences sociales des Religions, $1979, \mathrm{n}^{\circ} 48,1, \mathrm{p} .67$.

41. Sur l'histoire des différentes versions écrites de ce récit mythique, cf. LOCKE, op. cit., 1980 , p. 280 ss. Si l'on met de côté la Gopâlarâjavamçâvalî du xıve siècle, qui ne fait que mentionner l'arrivée de Matsyendranâth sous Narendradeva, le premier texte à citer le mythe, sous une forme très primitive, est le Swayambhu Purâna, un texte bouddhique daté du $\mathrm{Xv}^{\mathrm{c}}$ siècle. La légende apparaît de manière plus complète dans un manuscrit du XVII siècle appelé Matsyendrapadyasatakam, écrit sans doute sur les instructions du roi Srinivas Malla. Il est difficile de savoir quand la version néwari à laquelle je me réfère ici (n. 34) a été exactement composée, car le manuscrit dont Asakaji Vajracarya s'est servi pour publier son récit a disparu. Elle doit cependant remonter de toute évidence à l'époque Malla et - comme nous le verrons plus loin - au $\mathrm{XVII}^{\mathrm{e}}$ siècle. La triade prêtre, roi et agriculteur n'apparaît nettement qu'à partir de cette version néwari. Elle sera reprise plus tard par les versions népali citées dans les chroniques du XIX ${ }^{\mathrm{e}}$ siècle.

42. Selon certaines versions, le Jyâpu (ou Mâli) était accompagné de sa femme (Mâlini) et tous deux portaient des offrandes ; cf. par exemple S. LÉVI, op. cit., t. I, p. 349.

43. LocKE, op. cit., 1973, p. 48. La chronique Gopâlarâjavamçâvalî (XIV' siècle) ne cite que Narendradeva et Bandhudatt.

44. LoCKe, op. cit., 1980, p. 248. Tel Agri dans la théogonie védique, Matsyendranâth possède également de nombreux traits omnivalents. Il n'est pas seulement le symbole unifié du corps social, il exprime aussi la totalité des dieux du panthéon hindou. Selon la légende, tous les dieux vinrent rendre hommage à Matsyendranâth lorsque ce dernier entra dans la Vallée. Tous l'escortèrent en grande cérémonie jusqu'à son nouveau sanctuaire : "Brahma balayait la route en chantant les Védas; Visnu soufflait dans sa conque, Mahâdeva répandait l'eau lustrale ; Indra tenait l'ombrelle ; Yama brûlait l'encens ; Varuna répandait l'eau de pluie ; Kuvera, les richesses ; Agni, l'éclat ; Vâyu portait la bannière, Nairritya écartait les obstacles, Îçâna dispersait les démons. Bandhudatt et Narendradeva seuls voyaient ce spectacle merveilleux; le vulgaire n'y apercevait que des oiseaux et des bêtes "; S. LÉVI, op. cit., vol. 1, p. 350. On retrouve cette idée dans le char du dieu. Ce char porte en effet les représentations de quatre animaux, chacun symbolisant un dieu particulier : un cheval (= Sûrya), un taureau (= Çiva), un Garuda (= Visnu), un cygne ( = Brahmâ). 
45. Voir en particulier G. Toffin, « Les rites funéraires des hautes castes hindouistes néwar (Népal) ", dans Les hommes et la mort ; rituels funéraires à travers le monde, textes réunis et présentés par J. GuiarT, Paris, Le Sycomore-Objets et Mondes, 1979, pp. 242-252, à propos de la triade sacerdotale Brâhmane Râjopâdhyâya, prêtre tantrique Karmâcârya et astrologue Joçi durant les rituels.

46. D. WRIGHT, History of Nepal, Calcutta, Ranjan Gupta, 1958 (1 $1^{\text {re }}$ édition 1877), p. 126. Selon la Padmagirivamçâvalî, la population de la Vallée aurait été divisée en 36 jât et non en 64 ; cf. B. J. HASRAT, History of Nepal as told by its own and Contemporary Chroniclers, Hoshiarpur, V. V. Research Institute Book Agency, 1971, pp. 55-56.

47. A. Michaels, "Zur Deçoddhârapûjâ in Deopatan ", 1988, manuscrit non publié aimablement communiqué par l'auteur. Le rituel du deçoddhârapûjâ, qui a lieu tous les ans près de Deopatan, implique par exemple une répartition des officiants selon le système des quatre varna.

48. Selon Locke, l'actuel temple de Matsyendranâth à Patan daterait lui aussi du xvir siècle, op. cit., 1980 , p. 253 , ce qui tendrait à prouver que les rois de cette ville auraient cherché à déplacer à cette époque le centre festif des cérémonies vers Patan. Il ne s'agit malheureusement que d'une tradition orale qu'aucun document historique ne supporte.

49. HaSRat, op. cit., p. 69.

50. LOCKE, op. cit., 1980, p. 340.

51. Sur les aspects politiques et économiques de ces royaumes aux $\mathrm{xv}^{\mathrm{e}-\mathrm{XvIII}} \mathrm{e}^{\mathrm{e}}$ siècles, la source essentielle est D. R. Regmi, Medieval Nepal, t. II, Calcutta, K. L. Mukhopadhyaya, 1966.

52. LocKE, op. cit., 1973, p. 47. Contrairement à toutes les évidences historiques et les versions anciennes qui parlent de Bungamati, cette version (néwarie) situe le lieu de culte primitif de Matsyendranâth à Patan.

53. LoCKE, op. cit., 1980, p. 273, note 39.

54. Id., p. 272, n. 37.

55. LOCKE, op. cit., 1973, pp. 41-42. Ce passage est spécifique à la version néwarie éditée par Asakaji VAJRACARYA, op. cit., n. 34.

56. Les Nashi, un groupe tibéto-birman du sud de la Chine, prétendent eux aussi avoir pour ancêtre un chacal ; cf. J. Lemoine, "Mythes d'origine, mythes d'identification ", L'Homme, $1987, \mathrm{n}^{\circ} 1$, p. 83. En Inde, le chacal est souvent associé à la déesse ; cf. par exemple, F. Bhattacharya, "La déesse et le royaume selon le Kâlaketu Upâkhyâna du Candî Mangala ", Purushartha, Paris, Éditions de l'EHESS, 5, 1981, p. 23.

57. Bouillier, op. cit., n. 20, pp. 134-136.

58. Sur l'histoire des Kânphatâ Yogî dans la vallée de Kathmandou, cf. Bouillıer, op. cit., pp. 128-130.

59. Sur la royauté hindoue, la bibliographie est immense. Signalons un texte fondamental, basé sur les meilleures sources indiennes, P. V. KANE, History of Dharmaçastra, Poona, Bhandarkar Oriental Research Institute, vol. 3, 1946.

60. Sur les rapports entre Taleju et Paçupatinâth d'un côté, le roi de l'autre, cf. Toffin, op. cit., 1986 (note 28).

61. N. J. Allen, "The Coming of Macchendranâth to Nepal : Comments from a comparative point of view ", dans Oxford University Papers on India, vol. 1, pt. 1, N. J. ALLEN et alii éds., Delhi, 1986, pp. 75-102. Selon cet auteur, l'existence d'une quatrième fonction concernerait en fait l'ensemble de la pensée indo-européenne. Pour un point de vue récent sur ce sujet, voir E. B. LYLE, "Dumézil's three functions and Indo-European Cosmic Structure », History of Religions, vol. 22, n० 1, 1988, pp. 25-44.

62. AlLEN, id., p. 69.

63. Id., p. 82.

64. Tofrin, op. cit., 1979, pp. 64-68.

65. L'adjectif "segmentaire" est tiré de N. J. Allen, "The Ideology of the IndoEuropeans : Dumézil's Theory and the Idea of the Fourth Function ", International Journal of Moral and Social Studies, vol. 2, $\mathrm{n}^{\circ}$ 1, pp. 23-39. Cet article tente de systématiser l'idée d'une 


\section{AUTOUR DU RELIGIEUX}

quatrième fonction et de la situer dans la protohistoire des divers peuples indo-européens. Selon Allen, les anciens Indo-Européens avaient une idéologie de type « segmentaire » en rapport avec une structure sociale du même type.

66. G. W. BRIGGs, Gorakhnâth and the Kânphatâ Yogîs, Delhi, Motilal Banarsidass, 1973,

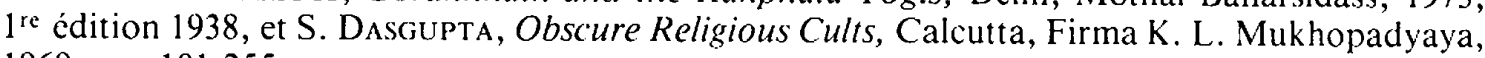
1969 , pp. 101-255.

67. Cité par V. Boullultr, " Des prêtres du pouvoir ", dans Prêtrise, pouvoirs et autorité en Himalaya, V. Boulliter et G. Torrin éds, $\mathrm{n}^{\circ}$ spécial de Purushartha, 12, 1988.

68. E. T. AtKinson, Religions in the Himalayas, Delhi, Cosmo Publications, 1974, p. 816.

69. Allen, op. cit., 1986, p. 100.

70. Id., p. 100.

71. C. Malamoud, "Sémantique et rhétorique dans la hiérarchie hindoue des buts de l'homme ", Archives européennes de Sociologie, 1982, XXIII, pp. 215-238.

72. Dublisson, op. cit., 1985, pp. 110-114.

73. All.en, op. cit., 1987, p. 34.

74. Rappelons ce court passage de Dumézil : «A mon avis, dans la recherche mythologique, deux règles de bon sens s'imposent : pour qu'on soit en droit de reconnaître une intention de classement trifonctionnel, il faut que les trois termes, dans la syntaxe et plus encore dans la penséc, soient homogènes (trois dons ou qualités d'un dieu, trois prières des hommes, etc.) ; il faut écarter toute cxégèse qui, pour une, à plus forte raison pour deux des fonctions, se fonderait sur l'interprétation sollicitée de termes équivoques ou imprécis », Les dieux souverains des Indo-Européens, op. cil., p. 224.

75. En particulier C. Ginzburg, Mythes, emblèmes, traces. Morphologie et histoire, Paris, Flammarion, 1989, p. 180 ss (chapitre intitulé « Mythologie germanique et nazisme. Sur un ancien livre de Georges Dumézil ", paru préalablement dans Annales ESC, 1985, n 4). Dumézil a répondu vigoureusement (et à juste titre) à ce texte: "Science et politique. Réponse à Carlo Ginzburg ", Annales ESC, 1985, n 5, pp. 985-989. Les médiévistes français ont aussi beaucoup glosé sur la question : par exemple, G. Duby, Les trois ordres ou l'imaginaire du féodalisme, Paris, Gallimard, 1978, et J. LE Goff, "Notes sur la société tripartic, idéologie monarchique et renouveau économique dans la chrétienté du $\mathrm{IX}^{\mathrm{e}}$ siècle au $\mathrm{XII}^{\mathrm{e}}$ siècle ", dans Pour un autre Moyen Age, Paris, Gallimard, 1977, ainsi que « Les trois fonctions indo-européennes, l'historien et l'Europe féodale ", Annales ESC, 1979, n 6, pp. 1187-1215.

76. C. LÉVi-Strauss, dans Discours de réception de $M$. Georges Dumézil à l'Académie française et réponse à $M$. Claude Lévi-Strauss, Paris, Gallimard, 1979, p. 74. Cette définition n'est ccpendant guère satisfaisante : qu'est-ce qu'une forme « vide »? Une catégorie fondamentale de l'entendement? La trifonctionnalité serait-elle inscrite dans le patrimoine génétique du genre humain ? On peut sérieusement s'interroger sur l'existence d'une telle forme abstraite décontextualisée.

77. G. DuBy, op. cit., n. 75, p. 20.

78. Pour Dumézil en revanche, le mot idéologie a un sens beaucoup plus large (trop large sans doute) : "J'entends par " idéologie" l'inventaire des idées directrices qui commandent la réflexion et la conduite d'une société ", dans L'oubli de l'homme et l'honneur des dieux, Paris, Gallimard, 1985 , p. 312.

79. J'emprunte cette distinction à Emmanuel Terray, compte rendu de l'ouvrage de C. Geertz (Negara, The Theatre-State in the XIXth Century Bali, 1980) dans L'Homme, 1984, XXIV, 1, p. 116. Elle est assez proche de l'opposition entre « ordres conçus " et " ordres vécus" proposée par Lévi-Strauss dans Anthropologie structurale, Paris, Plon, 1958.

80. Toffin, op. cit., 1986, p. 80.

81. A. M. Hocart, Kingship, chap. xviII, Oxford, 1927. 